\title{
Treatment of hypothyroidism with levothyroxine plus liothyronine: a randomized, double-blind, crossover study
}

\author{
Juliana Kaminski', Fabíola Yukiko Miasaki', \\ Gilberto Paz-Filho', Hans Graf', Gisah Amaral de Carvalho'
}

${ }^{1}$ Serviço de Endocrinologia e Metabologia (SEMPR), Departamento de Medicina Interna, Hospital das Clínicas da Universidade Federal do Paraná (HC-UFPR), Curitiba, PR, Brasil ${ }^{2}$ Genome Sciences Department, The John Curtin School of Medical Research, The Australian National University, Canberra, ACT, Australia

\section{Correspondence to:}

Gisah Amaral de Carvalho Av. Agostinho Leão Júnior, 285 80030-110 - Curitiba, PR, Brasil carvalho.gisah@gmail.com

Received on Sept/24/2015 Accepted on Jan/26/2016

DOI: 10.1590/2359-3997000000192

\begin{abstract}
Objective: To compare the effects of a unique fixed combination levothyroxine/liothyronine (LT4/LT3) therapy in patients with primary hypothyroidism. Subjects and methods: This is a randomized, double-blind, crossover study. Adults with primary hypothyroidism $(n=32$, age $42.6 \pm 13.3,30$ females) on stable doses of LT4 for $\geq 6$ months ( 125 or $150 \mu \mathrm{g} /$ day) were randomized to continue LT4 treatment (G1) or to start LT4/LT3 therapy $(75 / 15 \mu \mathrm{g} /$ day; G2). After 8 weeks, participants switched treatments for 8 more weeks. Thyroid function, lipid profile, plasma glucose, body weight, electrocardiogram, vital signs, and quality of life ( $\mathrm{QOL})$ were evaluated at weeks 0,8 and 16 . Results: Free T4 levels were significantly lower while on LT4/LT3 (G1: $1.07 \pm 0.29$ vs. $1.65 \pm 0.46$; G2: $0.97 \pm 0.26$ vs. $1.63 \pm$ $0.43 \mathrm{ng} / \mathrm{dL} ; \mathrm{P}<0.001)$. TSH and T3 levels were not affected by type of therapy. More patients on LT4/ LT3 had T3 levels above the upper limit (15\% vs. $3 \%$ ). The combination therapy led to an increase in heart rate, with no significant changes in electrocardiogram or arterial blood pressure. Lipid profile, body weight and $\mathrm{OoL}$ remained unchanged. Conclusions: The combination therapy yielded significantly lower free T4 levels, with no changes in TSH or T3 levels. More patients on LT4/T3 had elevated T3 levels, with no significant alterations in the evaluated outcomes. No clear clinical benefit of the studied formulation could be observed. Future trials need to evaluate different formulations and the impact of the combined therapy in select populations with genetic polymorphisms. Arch Endocrinol Metab. 2016;60(6):562-72
\end{abstract}

\section{Keywords}

Clinical trial; combined modality therapy; cross-over studies; hypothyroidism; levothyroxine; triiodothyronine; liothyronine; quality of life; randomized

\section{INTRODUCTION}

L evothyroxine sodium (LT4) is the drug of choice for the treatment of patients with hypothyroidism (1-5). The LT4 formulations available have a half-life of six days and provide fairly stable blood levels of thyroxine (T4) after ingestion of an oral daily dose (6). When treating patients with hypothyroidism, normal blood levels of TSH and free T4 (fT4) are achieved in most patients, with improvements in hypothyroid signs and symptoms.

However, approximately $5-10 \%$ of patients continue to report symptoms of hypothyroidism, despite their TSH levels being within the normal reference range (7). Mounting evidence suggests that LT4 monotherapy cannot assure a euthyroid state in the blood and in all tissues simultaneously, and that normal serum thyroidstimulating hormone (TSH) levels in patients receiving LT4 reflect only pituitary euthyroidism (8). This could be attributed to the fact that the peripheral conversion from T4 to triiodothyronine (T3) is not sufficient to restore normal T3 levels. In animal studies, only the combination levothyroxine/liothyronine (the synthetic form of triiodothyronine; LT4/LT3) ensured euthyroidism in all tissues of thyroidectomized rats (9).

In humans, several clinical trials have evaluated whether LT4/LT3 combination therapy was able to reverse overt hypothyroidism and improve symptoms and quality of life (QoL). The results from the first randomized, double-blind, crossover trial were reported in 1970. These showed no positive results regarding patient preference toward LT4/LT3 therapy and revealed a high incidence of hyperthyroid symptoms (possibly due to excessive doses of LT4/LT3) (10). In 1999, Bunevicius and cols. described an increase in well-being, mood and psychometric functionality in patients treated with LT4/LT3 (11), and similar results 
were replicated by another group (12). Those findings could not be further replicated by other studies, and recent meta-analyses of those trials did not show any evidence supporting a superior effect of combination treatment $(13,14)$. However, in the clinical setting, some patients who complain of hypothyroid symptoms (despite having normal TSH and fT4 levels) have mentioned improvements when empirically treated with LT4/LT3 and preferred that type of therapy (15). Therefore, it is still unclear whether the combination therapy LT4/LT3 is superior to LT4 monotherapy in patients with hypothyroidism.

The aim of the present study was to compare the effects of a unique, fixed combination LT4/ LT3 therapy (75 $\mu \mathrm{g}$ of LT4 and $15 \mu \mathrm{g}$ of LT3, once a day) on thyroid hormone levels, body weight, vital signs, metabolic parameters, and QoL of patients with primary hypothyroidism.

\section{SUBJECTS AND METHODS}

\section{Study subjects}

The study was approved by the Federal University Hospital of Paraná Ethics Committee, and written informed consent was obtained from all study participants, who were recruited from the Clinical Hospital of the Federal University of Paraná, Curitiba, Brazil. Inclusion criteria were participants of any gender, between 15 and 65 years old, with an established diagnosis of primary hypothyroidism, who had received stable doses of LT4 during the previous six months (125 or $150 \mu \mathrm{g} /$ day). Exclusion criteria were: diabetes mellitus or serious concomitant diseases (such as liver, renal or heart failure); use of drugs or substances that alter the pharmacokinetics and measures of serum TSH and of thyroid hormones; pregnancy; and use of hormonal contraception. Participants with diagnosis of depression were not excluded, provided they had been receiving adequate antidepressant treatment for the previous six months.

\section{Study design}

This was a randomized, double-blind, crossover study. One group of participants was randomized to continue receiving their usual dose of LT4 for 8 weeks, followed by use of combination therapy LT4 plus LT3 for 8 more weeks (Gl). The participants included in the second group (G2) were randomized to switch their usual therapeutic regimen to the combination therapy LT4/ LT3 for 8 weeks and to go back to their usual LT4 dose for another 8 weeks. Participants received capsules containing either their usual dose of LT4 (125 $\mu \mathrm{g}$ or $150 \mu g$; Euthyrox, Merck S/A, Brazil) or LT4/LT3 (75 $\mu \mathrm{g}$ of LT4, plus $15 \mu \mathrm{g}$ of LT3; Novothyral, Merck KGaA, Germany). Participants were advised to take their medication once daily, half an hour before breakfast. At the end of each eight-week period, participants received another batch of capsules. Drug dispensing was performed by one unblinded investigator (G.A.C.). This individual did not participate in the assessment of the results. Adherence to the therapy was assessed by direct questioning during follow-up visits and pill counting. Adverse events were evaluated by standard anamnesis and physical examination.

Participants were evaluated at baseline and at the end of each 8-week period. At each visit, venous blood samples were collected from all participants after a 12hour fast in order to measure serum TSH, total T3, fT4, glucose, total cholesterol, HDL cholesterol and triglycerides.

\section{Laboratory methods}

TSH was determined in duplicates by Immulite ${ }^{\circledR} 2000$ chemiluminescence TSH third-generation kit (Diagnostic Products Corporation, CA, USA; reference values [RV] 0.4-4.0 mUI/L; sensitivity $0.002 \mathrm{mUI} / \mathrm{L}$; intra-assay coefficient of variation [CV], 3.8-12.5\%; and inter-assay CV, 4.6-12.5\%). Free T4 was measured in duplicates by Immulite $^{\circledR} 2000$ chemiluminescence enzymelinked immunosorbent assay kit (Diagnostic Products Corporation, CA, USA; RV, 0.8-1.9 ng/dL; sensitivity, $0.15 \mathrm{ng} / \mathrm{dL}$; intra-assay CV, 4.4\%-7.5\%; and inter-assay $\mathrm{CV}, 4.8 \%-9.0 \%)$. Total T3 was measured in duplicates by Immulite $^{\circledR} 2000$ chemiluminescence enzymelinked immunosorbent assay kit (Diagnostic Products Corporation, CA, USA; RV, 82-179 ng/dL; sensitivity, $19 \mathrm{ng} / \mathrm{dL}$; intra-assay $\mathrm{CV}, 4.4 \%-12 \%$; and inter-assay CV, $5.3 \%-15 \%)$. Glucose was measured by enzymatic method (Hexokinase II, Bayer, Germany). Serum total cholesterol, HDL cholesterol and triglycerides were measured by enzymatic colorimetric methods (Sera-Pak Cholesterol Fast Color kit, HDL Advia and Sera-Pak Triglyceride Fast Color kits, Bayer, Germany).

Body weight, resting heart rate and arterial blood pressure were measured at baseline and at the end of each treatment period. Resting heart rate and arterial blood pressure were measured in the sitting position. Twelve-lead electrocardiogram (ECG) was obtained at the end of each treatment period. 


\section{Quality of life evaluation}

At each visit, QoL was assessed using a disease-specific questionnaire adapted from the Health Related Quality of Life (HRQOL) questionnaire (16), which in turn was elaborated to detect impaired well-being in subjects with hypothyroidism. We selected 29 items from the HRQOL questionnaire and added four items: palpitation, insomnia, irritability and anxiety. Therefore, our questionnaire consisted of 33 items grouped into three categories: physical complaints (12 items), energy and general well-being ( 11 items), and mood and emotions (10 items). Scoring was based on a six-point scale from zero to five, with zero representing a more favorable state. Participants also completed a visual analog scale (VAS) at baseline, 8 weeks and 16 weeks that assessed overall well-being, interest in sex and ability to engage in physical activities, social interactions and work. In the VAS, scores from -2.5 (the worst possible state) to +2.5 (the best possible state) were given for each of the five questions in 0.25 -point increments (overall feeling, ability to engage in physical activity, ability to engage in social interaction, ability to work and interest in sex). Each patient was evaluated by the same blinded examiner during all three sessions (either J.K. or F.Y.M.).

\section{Statistical analysis}

Clinical and biochemical data were analyzed by oneway ANOVA, Dunn's multiple comparison test, paired or unpaired (where appropriate) $t$-test for variables with normal distribution, and Wilcoxon signed-rank test or Mann-Whitney $U$ test for variables without normal distribution. To compare sample proportions, a z-test was employed. Quality of life scores were analyzed by Friedman rank-sums test. Correlations between QoL scores and thyroid hormone levels were calculated using Spearman's or Pearson's correlation coefficients. All variables were tested for normality by KolmogorovSmirnov test. Analyses were performed using GraphPad Prism 5.04.

\section{RESULTS}

A total of 39 patients were considered for inclusion. Seven patients were excluded before randomization, one because of pregnancy, one because of divorce, two because of onset of diabetes mellitus, and three because of increased TSH levels during the previous six months (Figure 1).



Figure 1. CONSORT diagram.

Thirty-two participants who fulfilled the inclusion and exclusion criteria were recruited. Twenty-three participants $(71.9 \%)$ had autoimmune or idiopathic hypothyroidism, six (18.7\%) had post-surgical hypothyroidism acquired after therapy for differentiated thyroid carcinoma, and three $(9.4 \%)$ had radioiodineinduced hypothyroidism due to Graves' disease. Mean age was $42.6 \pm 13.3$ years old, and $94 \%$ were female. The median duration of hypothyroidism was 4.5 years (minimum 1 , maximum 33 years). The same proportion of participants was being treated with either $125 \mu \mathrm{g}$ or $150 \mu \mathrm{g}$ of LT4 per day. Participants were randomized to continue taking their usual LT4 dose $(\mathrm{Gl} ; \mathrm{n}=17)$ or to switch to the LT4/LT3 combination therapy $(\mathrm{G} 2 ; \mathrm{n}=15)$. Baseline clinical and biochemical data were similar for both groups (Table 1). Serum basal TSH levels ranged from 0.001 to $4.5 \mathrm{mU} / \mathrm{L}$ in $\mathrm{Gl}$ and from 0.001 to $8.425 \mathrm{mU} / \mathrm{L}$ in $\mathrm{G} 2$. Six patients had suppressed TSH as a result of treatment for thyroid carcinoma. On the contrary, some patients had increased TSH levels at the time of randomization. Ideally, serum basal TSH concentrations would be within normal range. However, we decided to keep all patients in the statistical analysis because each crossover patient served as his or her own control. 
Table 1. Baseline clinical and biochemical data

\begin{tabular}{|c|c|c|c|c|}
\hline & $\begin{array}{l}\text { Prior to randomization } \\
\qquad(\mathrm{n}=32)\end{array}$ & $\begin{array}{l}\text { Group } 1 \text { (G1) } \\
\quad(n=17)\end{array}$ & $\begin{array}{c}\text { Group } 2 \text { (G2) } \\
(n=15)\end{array}$ & P (group 1 vs. group 2) \\
\hline Age (years-old) & $42.6 \pm 13.3$ & $39.5 \pm 14.2$ & $46.1 \pm 11.86$ & 0.170 \\
\hline Gender (F:M) & $30: 2$ & $15: 2$ & $15: 0$ & 0.143 \\
\hline Participants on LT4 $125 \mu \mathrm{g} /$ day (\%) & 50 & 52.9 & 46.7 & 0.726 \\
\hline Time of hypothyroidism diagnosis (years) & $4.5(1-33)$ & $5(1-33)$ & $4(1-23)$ & 0.595 \\
\hline Autoimmune/idiopathic hypothyroidism (\%) & 71.9 & 58.8 & 86.7 & 0.080 \\
\hline Post-surgical hypothyroidism (\%) & 18.7 & 23.5 & 13.3 & 0.460 \\
\hline Radioiodine-induced hypothyroidism (\%) & 9.4 & 17.6 & 0 & 0.088 \\
\hline Body mass index $\left(\mathrm{kg} / \mathrm{m}^{2}\right)$ & $28.5 \pm 5.6$ & $27.3 \pm 5.0$ & $29.8 \pm 6.0$ & 0.211 \\
\hline Resting heart rate (beats per minute) & $76.7 \pm 9.8$ & $79.1 \pm 9.0$ & $74.1 \pm 10.3$ & 0.160 \\
\hline Systolic blood pressure $(\mathrm{mmHg})$ & $\begin{array}{c}120.0 \\
(90.0-150.0)\end{array}$ & $\begin{array}{c}120.0 \\
(100.0-140.0)\end{array}$ & $\begin{array}{c}120.0 \\
(90.0-150.0)\end{array}$ & 0.612 \\
\hline Diastolic blood pressure (mmHg) & $78.9 \pm 11.3$ & $77.1 \pm 11.2$ & $81.0 \pm 11.5$ & 0.335 \\
\hline TSH (mU/L) & $\begin{array}{c}0.309 \\
(0.001-8.425)\end{array}$ & $\begin{array}{c}0.078 \\
(0.001-4.500)\end{array}$ & $\begin{array}{c}0.535 \\
(0.001-8.425)\end{array}$ & 0.117 \\
\hline Total T3 (ng/dL) & $93.6 \pm 11.6$ & $93.2 \pm 11.6$ & $94.0 \pm 12.0$ & 0.847 \\
\hline Free T4 (ng/dL) & $1.26 \pm 0.26$ & $1.26 \pm 0.25$ & $1.26 \pm 0.28$ & 0.956 \\
\hline Glucose (mg/dL) & $99.0 \pm 12.5$ & $97.6 \pm 10.6$ & $100.5 \pm 14.5$ & 0.532 \\
\hline Total cholesterol (mg/dL) & $191.1 \pm 35.4$ & $188.8 \pm 36.9$ & $193.7 \pm 34.8$ & 0.706 \\
\hline $\mathrm{HDL}(\mathrm{mg} / \mathrm{dL})$ & $47.2 \pm 11.9$ & $47.5 \pm 12.4$ & $46.9 \pm 11.8$ & 0.891 \\
\hline Triglycerides (mg/dL) & $139.7 \pm 68.0$ & $144.5 \pm 75.0$ & $134.3 \pm 61.2$ & 0.679 \\
\hline
\end{tabular}

Note: results are shown as mean \pm standard deviation or median (minimum - maximum).

Over the 16-week period, significant changes were observed only for fT4 levels (one-way ANOVA P < 0.001 in both groups), with significantly lower levels observed while taking LT4/LT3 treatment $(1.07 \pm 0.29$ at week 16 vs. $1.65 \pm 0.46 \mathrm{ng} / \mathrm{dL}$ at week 8 in Gl; 0.97 \pm 0.26 at week 8 vs. $1.63 \pm 0.43 \mathrm{ng} / \mathrm{dL}$ at week 16 in
G2) (Figure 2A). T3 levels were similar over the study in G1 (one-way ANOVA P $=0.662$ ) and G2 (one-way ANOVA $\mathrm{P}=0.247)$, and median T3 levels were not affected by type of therapy (Figure 2B). Changes in TSH levels were not significant in Gl (one-way ANOVA $\mathrm{P}=$ 0.05 ) or in G2 (one-way ANOVA P = 0.819; Figure 2C).

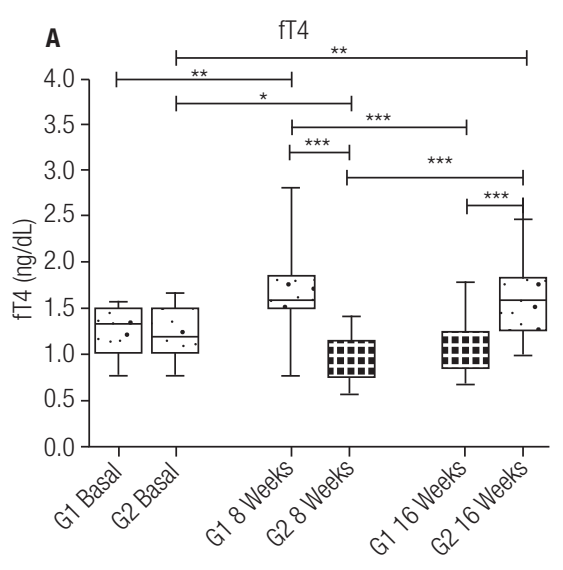

Figure 2. Changes in thyroid function tests.





${ }^{\star} \mathrm{P}<0.05 ;{ }^{* \star} \mathrm{P}<0.01 ;{ }^{\star \star \star} \mathrm{P}<0.001$.

G1: Group 1, on LT4 monotherapy; G2: Group 2, on LT4/LT3 combination therapy. 
The analysis of the results according to type of therapy (LT4 or LT4/LT3) showed that fT4 levels were significantly lower and resting heart rate was slightly higher while participants were taking the combination therapy. Other outcomes were similar, regardless of type of therapy (Table 2). Furthermore, five patients had T3 > $180 \mathrm{ng} / \mathrm{dL}$ while on LT4/LT3 (mean 239.4 $\pm 57.1 \mathrm{ng} / \mathrm{dL}$, highest $311.5 \mathrm{ng} / \mathrm{dL}$ ), whereas only one participant had increased T3 levels $(298.5 \mathrm{ng} / \mathrm{dL})$ when on LT4 therapy.

No significant adverse effects were reported, and all subjects completed the study. Although resting heart rate was slightly higher during the combination LT4/ LT3 treatment, it remained within the normal range. In addition, no arrhythmias were detected on resting ECG.

All participants responded to the adapted HRQOL questionnaire. Global median scores improved after randomization $(\mathrm{P}<0.001)$. Scores categorized into subgroups (physical complaints, energy/general wellbeing, and mood/emotions) also improved after randomization $(\mathrm{P}<0.05)$. However, there was no difference in global scores when comparing the two types of therapy $(\mathrm{P}=0.888)$. Furthermore, scores in each subgroup were similar for both treatments (all P > 0.05) (Figure 3). There were no correlations between global scores and thyroid hormone levels (fT4 and T3) at baseline or while on LT4 or LT4/ LT3 (all $\mathrm{P}>0.05$ ). However, there was a positive correlation between TSH and global scores while on LT4/LT3 $(r=0.4164, \mathrm{P}=0.018)$. Correlation analysis between scores by subgroups and thyroid hormone levels showed correlation only between energy/general well-being scores and TSH levels while on LT4/LT3 $(\mathrm{r}=0.4123, \mathrm{P}=0.019)$ and between mood/emotions scores and TSH levels, also while on LT4/LT3 ( $\mathrm{r}=$ $0.4011, \mathrm{P}=0.023)$.



Figure 3. Scores of quality of life, global and by type of complaint.

Box-plots depict median and range.

${ }^{\star} \mathrm{P}<0.05 ;{ }^{* \star} \mathrm{P}<0.01 ;{ }^{* \star} \mathrm{P}<0.001$.

By analyzing the 33 items of the adapted HRQOL questionnaire individually, we observed that 15 items had significantly different median scores when comparing scores at baseline to scores when on LT4 to scores of LT4/LT3 combination therapy $(\mathrm{P}<$ $0.05)$. According to these scores, QoL improved for all 15 of these specific items. When analyzing the effect of each type of therapy within these 15 items, lack of improvement from baseline was observed more frequently when participants were on LT4/LT3 combination therapy. Median scores did not change for 3 items while participants were on LT4/LT3, whereas scores remained the same for only one item while participants were on LT4. Conversely, compared

Table 2. Clinical data, thyroid function tests and biochemical results while on LT4 or LT4/LT3

\begin{tabular}{lccc}
\hline & On LT4 monotherapy & On LT4/LT3 combination therapy & P \\
\hline Body mass index $\left(\mathrm{kg} / \mathrm{m}^{2}\right)$ & $28.5 \pm 5.7$ & $28.4 \pm 5.7$ & 0.212 \\
Resting heart rate & $74.6 \pm 9.5$ & $77.4 \pm 9.2$ & 0.046 \\
Systolic blood pressure $(\mathrm{mmHg})$ & $118.1 \pm 13.3$ & $117.5 \pm 11.1$ & 0.875 \\
Diastolic blood pressure $(\mathrm{mmHg})$ & $74.1 \pm 8.7$ & 0.446 \\
TSH (mU/L) & $75.6 \pm 9.0$ & $0.638(0.013-9.500)$ & 0.540 \\
T3 (ng/dL) & $0.189(0.004-3.495)$ & $98.5(44.7-311.5)$ & 0.742 \\
Free T4 (ng/dL) & $103.8(40.0-298.5)$ & $1.03 \pm 0.28$ & $<0.0001$ \\
Glucose (mg/dL) & $1.64 \pm 0.44$ & $99.0 \pm 14.1$ & 0.191 \\
Total cholesterol (mg/dL) & $102.9 \pm 23.7$ & $190.9 \pm 34.9$ & 0.493 \\
HDL (mg/dL) & $188.4 \pm 31.3$ & $48.2 \pm 10.4$ & 0.286 \\
Triglycerides (mg/dL) & $49.1 \pm 10.1$ & $135.7 \pm 66.6$ & 0.623 \\
\hline
\end{tabular}

Note: results are shown as mean \pm standard deviation or median (minimum - maximum). 
to baseline, 14 items had their scores improved while on LT4; on LT4/LT3, lower scores were obtained in 12 items of the adapted HRQOL questionnaire. In a post hoc analysis, only two items were significantly different when the two treatments were compared. Median scores concerning brittle nails were lower while on LT4, and scores regarding shortness of breath were lower while on LT4/LT3. Concerning the four items that were added to the original questionnaire (palpitation, insomnia, irritability and anxiety), no significant changes were observed between the two regimens (Table 3 ).

Table 3. Itemized scores of quality of life

\begin{tabular}{|c|c|c|c|c|c|c|c|c|}
\hline $\mathbf{N}$ & Symptom & $\begin{array}{c}\text { Prior to } \\
\text { randomization }\end{array}$ & On LT4 & On LT4/LT3 & $\begin{array}{l}\text { P value (baseline } \\
\text { vs. LT4 vs. LT4/ } \\
\text { LT3) }\end{array}$ & $\begin{array}{l}\text { P value } \\
\text { (baseline vs. } \\
\text { LT4) Post hoc }\end{array}$ & $\begin{array}{c}\text { P value } \\
\text { (baseline vs. } \\
\text { LT4/LT3) } \\
\text { Post hoc } \\
\end{array}$ & $\begin{array}{c}\text { P value (LT4 } \\
\text { vs. LT4/LT3) } \\
\text { Post hoc }\end{array}$ \\
\hline \multirow{12}{*}{ 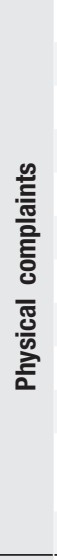 } & Feeling cold & $0(0-4)$ & $0(0-2)$ & $0(0-4)$ & 0.032 & 0.018 & 0.025 & 0.904 \\
\hline & Dry skin & $1.5(0-5)$ & $1.5(0-4)$ & $1.5(0-4)$ & 0.007 & 0.002 & 0.031 & 0.275 \\
\hline & Cold skin & $0(0-4)$ & $0(0-5)$ & $0(0-3)$ & 0.640 & NA & NA & NA \\
\hline & Tightening of clothes & $1(0-5)$ & $0(0-5)$ & $0(0-5)$ & 0.113 & NA & NA & NA \\
\hline & Dry hair & $0.5(0-5)$ & $0.5(0-5)$ & $0(0-5)$ & 0.076 & NA & NA & NA \\
\hline & Puffiness of hands & $1(0-3)$ & $0(0-3)$ & $0(0-3)$ & 0.013 & 0.006 & 0.013 & 0.778 \\
\hline & Brittle nails & $0(0-5)$ & $0(0-3)$ & $1(0-5)$ & 0.013 & 0.021 & 0.557 & 0.004 \\
\hline & Muscle cramps & $0.5(0-5)$ & $0(0-5)$ & $0(0-5)$ & 0.182 & NA & NA & NA \\
\hline & Shortness of breath & $1(0-4)$ & $1.5(0-3)$ & $1(0-5)$ & 0.018 & 0.453 & 0.006 & 0.038 \\
\hline & Swollen feet & $1(0-5)$ & $0(0-4)$ & $0(0-3)$ & 0.071 & NA & NA & NA \\
\hline & $\begin{array}{l}\text { Pins and needles in } \\
\text { hands/feet }\end{array}$ & $0(0-3)$ & $0(0-3)$ & $0(0-5)$ & 0.433 & NA & NA & NA \\
\hline & Palpitation & $1(0-5)$ & $1(0-5)$ & $0.5(0-5)$ & 0.182 & NA & NA & NA \\
\hline \multirow{11}{*}{  } & Feeling tired & $2.5(0-5)$ & $2(0-4)$ & $1(0-5)$ & 0.002 & 0.003 & 0.002 & 0.879 \\
\hline & $\begin{array}{l}\text { Feeling need for more } \\
\text { sleep }\end{array}$ & $1.5(0-5)$ & $1(0-3)$ & $1(0-4)$ & 0.587 & NA & NA & NA \\
\hline & Needing nap during day & $1(0-5)$ & $1(0-3)$ & $1(0-3)$ & 0.220 & NA & NA & NA \\
\hline & $\begin{array}{l}\text { Needing more time to do } \\
\text { daily chores }\end{array}$ & $1(0-5)$ & $0(0-4)$ & $0(0-3)$ & 0.001 & 0.003 & 0.001 & 0.758 \\
\hline & Insomnia & $0(0-5)$ & $0(0-5)$ & $0(0-5)$ & 0.658 & NA & NA & NA \\
\hline & Slower physically & $1(0-5)$ & $0(0-3)$ & $0.5(0-3)$ & 0.013 & 0.012 & 0.006 & 0.797 \\
\hline & Slower mentally & $2(0-5)$ & $1(0-4)$ & $1(0-5)$ & $<0.001$ & 0.002 & $<0.001$ & 0.340 \\
\hline & $\begin{array}{l}\text { Needing more time for } \\
\text { calculations }\end{array}$ & $1.5(0-5)$ & $1(0-5)$ & $1(0-4)$ & 0.044 & 0.013 & 0.128 & 0.307 \\
\hline & Going out less & $1(0-5)$ & $1(0-4)$ & $1(0-5)$ & 0.120 & NA & NA & NA \\
\hline & $\begin{array}{l}\text { No energy to get through } \\
\text { the day }\end{array}$ & $2(0-5)$ & $1(0-5)$ & $1(0-4)$ & 0.001 & $<0.001$ & 0.016 & 0.135 \\
\hline & Slowing of movements & $0(0-5)$ & $0(0-2)$ & $0(0-5)$ & 0.072 & NA & NA & NA \\
\hline \multirow{10}{*}{ 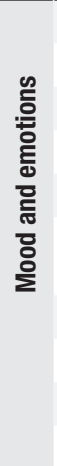 } & Feeling frustrated & $0(0-5)$ & $0(0-4)$ & $0(0-3)$ & 0.005 & $<0.001$ & 0.016 & 0.135 \\
\hline & Feeling discouraged & $2(0-5)$ & $1(0-5)$ & $1(0-5)$ & 0.002 & 0.001 & 0.004 & 0.538 \\
\hline & Difficulty concentrating & $1(0-5)$ & $1(0-4)$ & $1(0-4)$ & 0.093 & NA & NA & NA \\
\hline & Deterioration of memory & $1(0-5)$ & $1(0-4)$ & $1(0-4)$ & 0.066 & NA & NA & NA \\
\hline & Losing interest in sex & $1.5(0-5)$ & $1(0-5)$ & $1(0-5)$ & 0.476 & NA & NA & NA \\
\hline & $\begin{array}{l}\text { Losing interest in } \\
\text { activities/hobbies }\end{array}$ & $1(0-5)$ & $1(0-3)$ & $1(0-4)$ & 0.495 & NA & NA & NA \\
\hline & Feeling depressed & $1(0-5)$ & $0(0-5)$ & $0(0-5)$ & 0.021 & 0.005 & 0.118 & 0.191 \\
\hline & Feeling worthless & $0(0-5)$ & $0(0-2)$ & $0(0-3)$ & 0.971 & NA & NA & NA \\
\hline & Irritability & $2(0-5)$ & $1(0-5)$ & $1(0-5)$ & 0.011 & 0.033 & 0.003 & 0.359 \\
\hline & Anxiety & $2(0-5)$ & $1(0-5)$ & $1(0-5)$ & 0.069 & NA & NA & NA \\
\hline
\end{tabular}

Note: scores are shown as median (minimum - maximum). Scoring was based on a six-point scale from zero to five, with zero representing a more favorable state. 
Mean VAS scores were similar at baseline $(0.47 \pm$ $0.91)$, while on LT4 $(0.21 \pm 0.91)$, and while on LT4/ LT3 $(0.44 \pm 1.26$; one-way ANOVA P $=0.5175)$.

We performed a sub-analysis according the etiologies of hypothyroidism: autoimmune or idiopathic hypothyroidism, post-surgical hypothyroidism acquired after therapy for differentiated thyroid carcinoma and radioiodine-induced hypothyroidism due to Graves' disease. No significant changes were observed in VAS scores or QoL scores (global and subgroup scores) between the two treatments. We also performed a subanalysis for the group with high T3 levels (T3 > $180 \mathrm{ng} / \mathrm{dL}$ ), which showed no significant differences regarding QoL scores (global and subgroup scores), VAS scores, body mass index, arterial blood pressure or resting heart rate.

\section{DISCUSSION}

Currently, the drug of choice for the treatment of hypothyroidism is levothyroxine sodium (1-5), and LT4/ LT3 combination therapy should be considered solely as an experimental treatment modality (7). There is conflicting animal and human data suggesting that the addition of liothyronine to levothyroxine therapy improves outcomes (15). To clarify the role of liothyronine in the treatment of hypothyroidism, we conducted a randomized, double-blind, crossover clinical trial in which participants received LT4 alone for 8 weeks and LT4/LT3 for another 8 weeks. Our results suggest that the combination therapy LT4/LT3 significantly determines lower serum free T4 levels without significantly altering serum TSH, total T3, lipids, or fasting glucose levels. The type of treatment implemented did not affect body mass index and arterial blood pressure. Despite the fact that resting heart rate was slightly higher in participants taking the combination therapy, neither ECG alterations nor significant adverse effects were observed. Furthermore, no differences were observed regarding overall quality of life, and LT4/LT3 therapy was significantly superior to LT4 for only one of the 33 items evaluating quality of life.

Autoimmune thyroid disease is present in about $70 \%$ of hypothyroid individuals, and patients with autoimmune thyroid disease are at high risk of developing other autoimmune diseases. The development of these associated conditions might go unnoticed, and some patients have persistent nonspecific symptoms despite apparently adequate levothyroxine. In addition, there is the possibility that thyroid autoimmunity itself might give rise to nonspecific symptoms, independent of thyroid function (8).

The adult thyroid gland secretes all the circulating $\mathrm{T} 4$ and $20 \%$ of T3 present in the blood. The remaining $80 \%$ of the circulating $\mathrm{T} 3$ derives from peripheral 5 '-deiodination of the secreted T4 (17). Evidence from thyroidectomized animal and human studies suggests that thyroid hormone replacement therapy in the form of LT4 is not sufficient to lead to euthyroidism or to replenish $100 \%$ of the circulating and tissular T3, even assuming that peripheral conversion from $\mathrm{T} 4$ to $\mathrm{T} 3$ is normal $(18,19)$. In fact, a true euthyroid state (in plasma and tissue) may be attained only when LT4/ LT3 combination therapy is employed (9). This piece of evidence, along with the observation that many hypothyroid patients do not have their symptoms improved with LT4 therapy alone despite normal thyroid function tests, led to the development of human trials assessing the efficacy of LT4/LT3 in the treatment of hypothyroidism.

To date, 15 clinical trials have evaluated the combination therapy of LT4 plus synthetic liothyronine in patients with hypothyroidism [reviewed by EscobarMorreale and cols. (15)], and one study evaluated desiccated thyroid extract containing both $\mathrm{T} 3$ and T4 (20). Clear benefits of the combination therapy were only observed among two groups from Lithuania and Denmark, which reported improvements in mood, wellbeing and psychometric functionality $(11,21)$, along with better scores of QoL, depression and anxiety (12). In the first trial showing positive results, the significant benefit of the combination therapy was evident only in a group of athyreotic subjects who had previously had thyroid cancer. Thus, it is not clear whether the results were related to the cause of hypothyroidism (21). In the other positive study, treatment dose was titrated to aim for stable serum TSH levels. Significant improvements in QoL, depression and anxiety scales were observed with a considerably lower T4:T3 ratio of 2.5:1 (12). The study with the largest sample size and longest follow-up was conducted by Saravanan and cols. In that study, 697 patients with primary hypothyroidism were initially randomized and treated in a non-crossover, double-blind design at a T4:T3 weight ratio of 5:1. That study reported a slight improvement in mood, QoL and anxiety after 3 months of the combination treatment, which was not confirmed subsequently after 1 year (22). Furthermore, a meta-analysis evaluating 
11 randomized controlled trials with a total of 1,216 patients concluded that there is no evidence supporting the superiority of LT4/LT3 combination therapy regarding improvements in bodily pain, mood, fatigue, QoL, cognition, body weight or blood lipids (13). Not even patients with depression (11), high dissatisfaction with LT4 therapy (23), psychiatric symptoms (24), or fatigue (25) benefited from the combination therapy.

In our study, we evaluated 32 participants with stable, treated primary hypothyroidism, most of them of autoimmune or idiopathic etiology. However, some patients were athyreotic following treatment for thyroid cancer or had hypothyroidism because of the administration of radioactive iodine therapy for Graves' disease. Also, both genders were included in the study; therefore, this heterogeneity may be a confounding factor, as previously observed (21). Instead of using a substitution approach to calculate the dose of LT4/ LT3, we recruited participants who were within a very limited LT4 daily dose range ( 125 or $150 \mu \mathrm{g} /$ day) and used a fixed combination approach. We administered LT4/LT3 at a fixed dose of $75 \mu \mathrm{g}$ of LT4 plus $15 \mu \mathrm{g}$ of LT3, regardless of their initial LT4 dose, in the same $5: 1$ weight ratio as previously evaluated in other studies $(12,22-24)$. Doses were not adjusted during the study period, as was done by Nygaard and cols. (12). To our knowledge, no other studies have employed such strict recruitment criteria, and the fixed dose of $75 \mu \mathrm{g}$ of LT4 plus $15 \mu \mathrm{g}$ of T3 has been evaluated only by one study (24). That study recruited participants taking any dose of LT4, and a substitution approach was employed to calculate the LT4/LT3 dose for a subgroup of patients (usual LT4 dose minus $25 \mu \mathrm{g}$ of LT4 plus $15 \mu \mathrm{g}$ of LT3). Within this subgroup of patients that was probably overtreated, half of the participants underwent TSH suppression and experienced increases in heart rate and significant weight loss. Nygaard and cols.'s study recruited patients on different daily doses of LT4; a few participants whose dose prior to randomization was 125 $\mu \mathrm{g} /$ day were treated with a dose that was close but not equal to ours (75 $\mu \mathrm{g}$ of LT4 $+20 \mu \mathrm{g}$ of T3). In the study by Clyde and cols., a few participants who were initially on LT4 $125 \mu \mathrm{g} /$ day received the same combination dose as the one employed in our study. However, the LT3 dose was administered twice daily (26).

We submitted participants to both types of therapy for 8 weeks each, which led to significantly lower plasma levels of fT4 while on LT4/LT3 therapy. This is an expected finding that was reported in a previous meta-analysis, which also reported no effect of the combination therapy on plasma TSH, total T3 or lipids (13). In our study, comparisons of results observed at baseline to those observed at 8 weeks and at 16 weeks also showed that $\mathrm{fT} 4$ levels were lower when participants were under LT4/LT3 therapy. Also, there were no changes in TSH and T3 levels over the 16-week period. Although we could not identify increases in T3 levels caused by the combination therapy, it is possible that these results are falsely low due to the short half-life of liothyronine, as well as the fact that blood samples were collected 24 hours after administration of the LT4/ LT3 tablets.

Although the T4:T3 ratio of 5:1 used in our study is similar to those used in other studies [but different than the 13:1-20:1 weight ratio recommended by the European Thyroid Association (7)], we have not assessed whether that dose led to both blood and tissular euthyroidism. Excessive doses of LT4/ LT3 may contribute to increases in resting heart rate (27), bone remodeling markers (24,28-30) and serum aminotransferases (30), leading to clinical manifestations of hyperthyroidism (31). In our study, we observed a borderline significant increase in heart rate by 3 beats/minute, which did not lead to adverse events. Even though atrial arrhythmias have been reported in two studies in which patients were overtreated during the combination treatment $(10,32)$, we did not detect arrhythmias on resting 12-lead ECG. Furthermore, no significant changes were detected in arterial blood pressure, in concordance with previous clinical trials (10-12,22-24,32).

We also evaluated body weight (as this can be affected by slight variations in thyroid hormone levels), body composition and resting energy expenditure (33). In one previous study, significant decreases in body weight after the combination therapy were observed. However, the combination therapy led to overtreatment in many patients, obtaining a median TSH of $0.07 \mathrm{mU} / \mathrm{L}$ (24). Nevertheless, similar to our results, other clinical trials did not reveal significant changes in body weight after LT4/LT3 therapy $(11,12,22,23)$.

Overt hypothyroidism is classically associated with negative effects on lipid metabolism (34), which improves significantly with LT4 therapy $(35,36)$. However, very few trials showed a benefit of the LT4/ LT3 combination treatment on blood lipids (37). In our study, we did not observe significant changes in 
total cholesterol, LDL-cholesterol, HDL-cholesterol or triglycerides, in concordance with previous studies $(11,22)$. Additionally, the combination therapy did not affect fasting glucose levels. Since we did not measure fasting insulin levels, we could not assess the impact of LT4/LT3 therapy on insulin sensitivity.

Hypothyroidism may induce affective and cognitive dysfunction $(38,39)$. Most studies have assessed changes in mood, cognition function and QoL during combination therapy with LT4/LT3 (11,12,21,23$26,28,30-32,40,41)$. Two meta-analyses including 10 (14) and 11 (13) of these studies showed no improvement in bodily pain, well-being, mood, fatigue, QoL or cognition. It should be noted that the evaluation of QoL, well-being, mood and thyroid symptoms is not standardized across studies, and different instruments (such as the SF-36, Hamilton Scales of Depression and Anxiety, and Thyroid Symptom Questionnaire) have been employed. In our study, we adapted and translated to Portuguese the questionnaire developed and employed by Jaeschke and cols. (16) and Clyde and cols. in their clinical trials (26). The analysis of our adapted HRQOL questionnaire revealed no significant changes in global scores or in scores within each category (physical complaints, energy and wellbeing, and mood and emotions). Interestingly, in 15 items of the questionnaire, we observed improvement in the scores throughout the study period when compared with baseline scores. This could be explained by the Hawthorne effect, or the tendency of patients to describe improvement in health simply due to participation in a trial (6). However, when excluding the baseline scores and performing the post hoc analysis between the two treatments, only two out of the 33 evaluated items had significantly different scores. Participants on LT4 reported improvement in the "brittle nails" complaint, whereas those on LT4/LT3 reported reduced shortness of breath. In hypothyroid patients, breathing complaints are unspecific and their clinical importance is unclear. By contrast, fragile nails are the most prevalent symptom in patients with nail involvement in hypothyroidism (42). Nevertheless, it is unclear why this symptom was improved by LT4 therapy. When correlating scores with TSH, fT4 and T3 levels, we could identify only moderate correlation between TSH and global scores, between TSH and energy/general well-being scores, and between TSH levels and mood/emotions scores (all while on LT4/ LT3). The lack of effect on QoL was also evident in the analysis of the scores obtained from the VAS.
Whereas a previous study showed that LT4 monotherapy leads to no change in serum free T3 in the first 4 hours post-dose, LT4/LT3 therapy can determine a marked rise by $42 \%$ in serum free $\mathrm{T} 3$ within the first 4 hours after ingestion of LT4/LT3 (27). This acute rise can cause hyperthyroid symptoms that were not detected by our adapted HRQOL questionnaire. We added four items to that questionnaire (palpitation, insomnia, anxiety and irritability) because we postulated that LT4/LT3 therapy could induce some complaints that would have been missed by the original HRQOL questionnaire. Among those four items, only irritability scores improved from baseline with both therapies. However, those scores were not significantly different from each other.

We performed a 16-week crossover trial to eliminate any carryover effect. By doing so, we observed that TSH levels while on LT4 or LT4/LT3 were similar, and TSH levels remained fairly constant throughout the study. Moreover, we used a commercially available presentation of LT4/LT3 that can be applied in clinics, thereby avoiding dosing errors when compounding liothyronine. However, we did not assess patient preference, which might be higher when taking LT4/ LT3 and unrelated to improvements (or lack thereof) in quantitative scores (20). Furthermore, we did not employ a washout period between the LT4 treatment and the combined therapy, to avoid submitting our participants to unnecessary clinical hypothyroidism. In addition, oral liothyronine has a shorter half-life, and significant results could have been observed if we instead had administered a constant, steady supply of T3 by means of enteric, transdermal or intramuscular sustained-release preparation or twice daily (8). Different results could have been observed in a more homogeneous, larger sample, but several similar trials evaluated $\leq 40$ participants, with adequate statistical power $(11,21,25,28,30,32,37,41)$. Similarly, the duration of our study may not have been long enough to detect changes in peripheral parameters. However, combination therapy has been evaluated for $\leq 8$ weeks in other similar trials $(10,11,21,28)$. Finally, despite being validated in English, our HRQOL questionnaire did not undergo validation in Portuguese.

Despite the fact that our study and previous metaanalyses failed to find clear benefits in the treatment of hypothyroid individuals with combination LT4/LT3, it is possible that a subgroup of patients with deiodinase 2 (DIO2) polymorphisms can benefit from combination 
therapy (43). One such polymorphism in the D2 gene (Th92Ala) is associated with reduced T4 to T3 activation in skeletal muscle and thyroid, as well as alterations in thyroid-pituitary feedback. A suggestive indication to the presence of this polymorphism could be a higherthan-normal ratio of free T4 to free T3 $(6,44)$. Other polymorphisms in the phosphodiesterase $8 \mathrm{~B}$ (PDE8B) may also alter the carrier's genetically determined TSH set-point, leading to sustained hypothyroid symptoms despite normal TSH levels (7). To date, it is still unclear whether polymorphisms play a role in response to therapy in patients with hypothyroidism (45-47).

Even though animal studies support combined levothyroxine plus liothyronine therapy, clinical trials in humans have not shown the advantages of that approach over administration of levothyroxine alone. The preference of some patients for combined therapy (found in some trials) may have a genetic background. Hence, this should be balanced against the possibility of adverse events resulting from the addition of liothyronine to levothyroxine. Currently available oral liothyronine preparations have an inadequate pharmacokinetic profile. Similarly, commercial preparations that contain levothyroxine and liothyronine contain an excess of the latter and do not mimic the proportion of levothyroxine to triiodothyronine present in normal human thyroidal secretion. Future studies need to evaluate the effect of long-acting, slow-release forms of T3, which mimic normal physiological endogenous T3 production. Furthermore, prospective and longer trials are required to further evaluate the response to the combination LT4/LT3 treatment in patients with the polymorphisms in genes affecting thyroid economy.

Acknowledgments: the authors thank Mr. Angad Johar for revising the manuscript.

Disclosure: Merck S/A, Brazil, provided Novothyral and Euthyrox capsules. Merck S/A, Brazil, had no role in study design, data analysis and interpretation of data, writing of the manuscript, or decision to submit the manuscript for publication. All authors had and have full access to the study data.

\section{REFERENCES}

1. Okosieme O, Gilbert J, Abraham P, Boelaert K, Dayan C, Gurnell $M$, et al. Management of primary hypothyroidism: statement by the British Thyroid Association Executive Committee. Clin Endocrinol (Oxf). 2016;84(6):799-808.

2. Jonklaas J, Bianco AC, Bauer AJ, Burman KD, Cappola AR, Celi FS, et al. Guidelines for the treatment of hypothyroidism: prepared by the American Thyroid Association task force on thyroid hormone replacement. Thyroid. 2014;24:1670-751.

3. Paz-Filho G, Graf H, Ward LS. Comparative analysis of the new guidelines and consensuses for the management of hypothyroidism, thyroid nodules, and differentiated thyroid cancer. Arq Bras Endocrinol Metabol. 2013;57:233-9.

4. Brenta G, Vaisman M, Sgarbi JA, Bergoglio LM, Andrada NC, Bravo PP, et al.; Task Force on Hypothyroidism of the Latin American Thyroid Society (LATS). Clinical practice guidelines for the management of hypothyroidism. Arq Bras Endocrinol Metabol. 2013;57:265-91.

5. Burch HB, Burman KD, Cooper DS, Hennessey JV. A 2013 survey of clinical practice patterns in the management of primary hypothyroidism. J Clin Endocrinol Metab. 2014;99:2077-85.

6. Biondi B, Wartofsky L. Combination treatment with T4 and T3: toward personalized replacement therapy in hypothyroidism? J Clin Endocrinol Metab. 2012;97:2256-71.

7. Wiersinga WM, Duntas L, Fadeyev V, Nygaard B, Vanderpump MP. 2012 ETA Guidelines: The Use of L-T4 + L-T3 in the Treatment of Hypothyroidism. EurThyroid J. 2012;1:55-71.

8. Wiersinga WM. Paradigm shifts in thyroid hormone replacement therapies for hypothyroidism. Nat Rev Endocrinol. 2014;10:16474.

9. Escobar-Morreale HF, del Rey FE, Obregon MJ, de Escobar GM. Only the combined treatment with thyroxine and triiodothyronine ensures euthyroidism in all tissues of the thyroidectomized rat. Endocrinology. 1996;137:2490-502.

10. Smith RN, Taylor SA, Massey JC. Controlled clinical trial of combined triiodothyronine and thyroxine in the treatment of hypothyroidism. Br Med J. 1970;4:145-8.

11. Bunevicius R, Kazanavicius G, Zalinkevicius R, Prange AJ Jr. Effects of thyroxine as compared with thyroxine plus triiodothyronine in patients with hypothyroidism. N Engl J Med. 1999;340:424-9.

12. Nygaard B, Jensen EW, Kvetny J, Jarlov A, Faber J. Effect of combination therapy with thyroxine (T4) and 3,5,3'-triiodothyronine versus T4 monotherapy in patients with hypothyroidism, a double-blind, randomised cross-over study. Eur J Endocrinol. 2009;161:895-902.

13. Grozinsky-Glasberg S, Fraser A, Nahshoni E, Weizman A, Leibovici L. Thyroxine-triiodothyronine combination therapy versus thyroxine monotherapy for clinical hypothyroidism: metaanalysis of randomized controlled trials. J Clin Endocrinol Metab. 2006;91:2592-9.

14. Ma C, Xie J, Huang $X$, Wang G, Wang Y, Wang $X$, et al. Thyroxine alone or thyroxine plus triiodothyronine replacement therapy for hypothyroidism. Nucl Med Commun. 2009;30:586-93.

15. Escobar-Morreale HF, Botella-Carretero JI, Morreale de Escobar G. Treatment of hypothyroidism with levothyroxine or a combination of levothyroxine plus L-triiodothyronine. Best Pract Res Clin Endocrinol Metab. 2015;29:57-75.

16. Jaeschke R, Guyatt G, Cook D, Harper S, Gerstein HC. Spectrum of quality of life impairment in hypothyroidism. Qual Life Res. 1994;3:323-7.

17. Abdalla SM, Bianco AC. Defending plasma $\mathrm{T} 3$ is a biological priority. Clin Endocrinol (Oxf). 2014;81:633-41.

18. Escobar-Morreale HF, Obregon MJ, Escobar del Rey F, Morreale de Escobar G. Replacement therapy for hypothyroidism with thyroxine alone does not ensure euthyroidism in all tissues, as studied in thyroidectomized rats. J Clin Invest. 1995;96:2828-38.

19. Gullo D, Latina A, Frasca F, Le Moli R, Pellegriti G, Vigneri R. Levothyroxine monotherapy cannot guarantee euthyroidism in all athyreotic patients. PLoS One. 2011;6:e22552.

20. Hoang TD, Olsen CH, Mai VQ, Clyde PW, Shakir MK. Desiccated thyroid extract compared with levothyroxine in the treatment of 
hypothyroidism: a randomized, double-blind, crossover study. J Clin Endocrinol Metab. 2013;98:1982-90.

21. Bunevicius R, Prange AJ. Mental improvement after replacement therapy with thyroxine plus triiodothyronine: relationship to cause of hypothyroidism. Int J Neuropsychopharmacol. 2000;3:167-74.

22. Saravanan P, Simmons DJ, Greenwood R, Peters TJ, Dayan CM. Partial substitution of thyroxine (T4) with tri-iodothyronine in patients on T4 replacement therapy: results of a large communitybased randomized controlled trial. J Clin Endocrinol Metab. 2005;90:805-12.

23. Walsh JP, Shiels L, Lim EM, Bhagat Cl, Ward LC, Stuckey BG, et al. Combined thyroxine/liothyronine treatment does not improve well-being, quality of life, or cognitive function compared to thyroxine alone: a randomized controlled trial in patients with primary hypothyroidism. J Clin Endocrinol Metab. 2003;88:454350.

24. Appelhof BC, Fliers E, Wekking EM, Schene AH, Huyser J, Tijssen $\mathrm{JG}$, et al. Combined therapy with levothyroxine and liothyronine in two ratios, compared with levothyroxine monotherapy in primary hypothyroidism: a double-blind, randomized, controlled clinical trial. J Clin Endocrinol Metab. 2005;90:2666-74.

25. Rodriguez T, Lavis VR, Meininger JC, Kapadia AS, Stafford LF. Substitution of liothyronine at a 1:5 ratio for a portion of levothyroxine: effect on fatigue, symptoms of depression, and working memory versus treatment with levothyroxine alone. Endocr Pract. 2005;11:223-33.

26. Clyde PW, Harari AE, Getka EJ, Shakir KM. Combined levothyroxine plus liothyronine compared with levothyroxine alone in primary hypothyroidism: a randomized controlled trial. JAMA. 2003;290:2952-8.

27. Saravanan P, Siddique $H$, Simmons DJ, Greenwood R, Dayan CM. Twenty-four hour hormone profiles of TSH, Free T3 and free T4 in hypothyroid patients on combined T3/T4 therapy. Exp Clin Endocrinol Diabetes. 2007;115:261-7.

28. Escobar-Morreale HF, Botella-Carretero Jl, Gomez-Bueno M, Galan JM, Barrios V, Sancho J. Thyroid hormone replacement therapy in primary hypothyroidism: a randomized trial comparing L-thyroxine plus liothyronine with L-thyroxine alone. Ann Intern Med. 2005;142:412-24.

29. Fadeyev VV, Morgunova TB, Sytch JP, Melnichenko GA. TSH and thyroid hormones concentrations in patients with hypothyroidism receiving replacement therapy with L-thyroxine alone or in combination with L-triiodothyronine. Hormones (Athens). 2005;4:101-7.

30. Regalbuto C, Maiorana R, Alagona C, Paola RD, Cianci M, Alagona G, et al. Effects of either LT4 monotherapy or LT4/LT3 combined therapy in patients totally thyroidectomized for thyroid cancer. Thyroid. 2007;17:323-31.

31. Valizadeh M, Seyyed-Majidi MR, Hajibeigloo $H$, Momtazi S, Musavinasab N, Hayatbakhsh MR. Efficacy of combined levothyroxine and liothyronine as compared with levothyroxine monotherapy in primary hypothyroidism: a randomized controlled trial. Endocr Res. 2009;34:80-9.

32. Siegmund W, Spieker K, Weike Al, Giessmann T, Modess C, Dabers $\mathrm{T}$, et al. Replacement therapy with levothyroxine plus triiodothyronine (bioavailable molar ratio $14: 1$ ) is not superior to thyroxine alone to improve well-being and cognitive performance in hypothyroidism. Clin Endocrinol (Oxf). 2004;60:750-7.
33. Boeving A, Paz-Filho G, Radominski RB, Graf H, Amaral de Carvalho $\mathrm{G}$. Low-normal or high-normal thyrotropin target levels during treatment of hypothyroidism: a prospective, comparative study. Thyroid. 2011;21:355-60.

34. Cappola AR, Ladenson PW. Hypothyroidism and atherosclerosis. $\mathrm{J}$ Clin Endocrinol Metab. 2003;88:2438-44.

35. Teixeira Pde F, Reuters VS, Ferreira MM, Almeida CP, Reis FA, Buescu $A$, et al. Lipid profile in different degrees of hypothyroidism and effects of levothyroxine replacement in mild thyroid failure. Transl Res. 2008;151:224-31.

36. Danese MD, Ladenson PW, Meinert CL, Powe NR. Clinical review 115: effect of thyroxine therapy on serum lipoproteins in patients with mild thyroid failure: a quantitative review of the literature. $J$ Clin Endocrinol Metab. 2000;85:2993-3001.

37. Fadeyev VV, MorgunovaTB, Melnichenko GA, Dedov II. Combined therapy with L-thyroxine and L-triiodothyronine compared to L-thyroxine alone in the treatment of primary hypothyroidism. Hormones (Athens). 2010;9:245-52.

38. Beydoun MA, Beydoun HA, Kitner-Triolo MH, Kaufman JS, Evans MK, Zonderman AB. Thyroid hormones are associated with cognitive function: moderation by sex, race, and depressive symptoms. J Clin Endocrinol Metab. 2013;98:3470-81.

39. Samuels $\mathrm{MH}$, Schuff KG, Carlson NE, Carello P, Janowsky JS. Health status, psychological symptoms, mood, and cognition in L-thyroxine-treated hypothyroid subjects. Thyroid. 2007;17:249-58.

40. Saravanan P, Visser TJ, Dayan CM. Psychological well-being correlates with free thyroxine but not free 3,5,3'-triiodothyronine levels in patients on thyroid hormone replacement. $\mathrm{J}$ Clin Endocrinol Metab. 2006;91:3389-93.

41. Sawka AM, Gerstein HC, Marriott MJ, MacQueen GM, Joffe RT. Does a combination regimen of thyroxine (T4) and 3,5,3'-triiodothyronine improve depressive symptoms better than T4 alone in patients with hypothyroidism? Results of a doubleblind, randomized, controlled trial. J Clin Endocrinol Metab. 2003;88:4551-5.

42. Razi A, Golforoushan F, Nejad AB, Goldust M. Evaluation of dermal symptoms in hypothyroidism and hyperthyroidism. Pak J Biol Sci. 2013;16:541-4.

43. Panicker V, Saravanan P, Vaidya B, Evans J, Hattersley AT, Frayling $\mathrm{TM}$, et al. Common variation in the $\mathrm{DIO} 2$ gene predicts baseline psychological well-being and response to combination thyroxine plus triiodothyronine therapy in hypothyroid patients. J Clin Endocrinol Metab. 2009;94:1623-9.

44. Wartofsky L. Combination L-T3 and L-T4 therapy for hypothyroidism. Curr Opin Endocrinol Diabetes Obes. 2013;20:460-6

45. Appelhof BC, Peeters RP, Wiersinga WM, Visser TJ, Wekking EM, Huyser J, et al. Polymorphisms in type 2 deiodinase are not associated with well-being, neurocognitive functioning, and preference for combined thyroxine/3,5,3'-triiodothyronine therapy. J Clin Endocrinol Metab. 2005;90:6296-9.

46. van der Deure WM, Appelhof BC, Peeters RP, Wiersinga WM, Wekking EM, Huyser J, et al. Polymorphisms in the brain-specific thyroid hormone transporter OATP1C1 are associated with fatigue and depression in hypothyroid patients. Clin Endocrinol (Oxf). 2008;69:804-11.

47. Wiersinga WM. Do we need still more trials on T4 and T3 combination therapy in hypothyroidism? Eur $\mathrm{J}$ Endocrinol. 2009;161:955-9. 